\title{
Technology Governance: Minding and Closing the Gaps in Africa
}

https://doi.org/10.36369/2616-9045/2021/v10i2a5

\section{SOKFA FRANCIS JOHN}

Postdoctoral Fellow

University of KwaZulu-Natal, South Africa

JohnS1@ukzn.ac.za

\begin{abstract}
Technological innovation is at the heart of human evolution and progress. It is a catalyst for human well-being and socio-economic development. The rapid advancement the world is currently witnessing in this regard also birth concerns and ambiguities around the tension between benefits of today's innovations and technologies and their actual and potential harm or risks. This paper outlines some key challenges to the global governance of emerging technologies to maximise benefits while preventing harm. The paper also identified some gaps in technology governance in Africa, their implications, and some key issues that need to be considered in closing these gaps. It argues that African governments, the corporate sector, academic institutions and other stakeholders need to begin to engage the current state of innovations and technologies and their possible futures and implications for the continent more critically and innovatively. This will require approaches informed by current needs and future thinking, are in sync with global trends, and prioritise Africa's interests and needs. The current decolonisation debates in Africa should specifically inform such approaches. That will address the emerging patterns of coloniality observed in the current technological landscape and prevent the future occurrence of such practices. Additionally, considering rural African populations and their importance to the continent's sustainable development, approaches to technological governance should also aim to centralise rather than marginalise rural communities. The paper concludes by highlighting some key areas of future research, such as investigating ways to achieve inclusive, just and equitable technological governance.
\end{abstract}

Keywords: innovation, technologies, Africa, governance, decolonisation

\section{Introduction}

Technological innovation is at the heart of human evolution and progress. It is a catalyst for human well-being and socio-economic development. However, it has also enabled some of the world's major atrocities. The rapid technological advancement the world is currently witnessing is heightening tension between the obvious positive impact and potential on the one hand, and the actual and potential harm, on the other. Innovative 
Fourth Industrial Revolution (4IR) technologies are bringing about immeasurable social and economic values, but can also have negative, harmful and unintended consequences (World Economic Forum \& Deloitte, 2020). For example, despite their widely acknowledged revolutionary benefits, debates are ongoing about how the decentralised nature of blockchain technology undermines global financial markets. The new forms of inequalities enabled by platforms such as Airbnb, the harmful and ethical questions raised by gene-editing innovations enabled by emerging advances in bioengineering (OECD., 2018). In recent years, leading technology companies have been under scrutiny for potentially harmful practices, including user privacy, datafication and ethical technology design. However, technology governance is increasingly necessary to avoid and mitigate harm while benefiting from technological innovations. According to the Organization for Economic Cooperation and Development (OECD., 2018), technology governance is the:

Process of exercising political, economic and administrative authority in the development, diffusion and operation of technology in societies. It can consist of norms (e.g. regulations, standards and customs), but can also be operationalised through physical and virtual architectures that manage risks and benefits. Technology governance pertains to formal government activities and the activities of firms, civil society organisations, and communities of practice. In its broadest sense, it represents the sum of the many ways in which individuals and organisations shape technology and how, conversely, technology shapes social order

This definition shows that technology governance includes a broad range of governance processes and activities and encompasses narrower concepts such as information technology (IT) governance or data governance. IT governance, for example, is a formal framework for organisations to manage better, specifically, information technology and ensure that their investments in IT is consistent with their business objectives, helps them manage risks and bring desired value (Joshi et al., 2018; Sirisomboonsuk et al., 2018). Technology governance, however, aims to minimise the potential harm of innovation and a broader range of technologies on societies while maximising their benefits. This requires specific legislation and processes concerning data, information technology, robotics, automation, biotechnology and several others, as well as a much broader approach that addresses fundamental issues across these technologies and throughout the process of innovation. However, technology governance is proving to be a challenging endeavour. Among other things, existing regulations and frameworks are limited in their ability to address questions raised by new technologies, and the technological landscape is changing so fast that governance policies are struggling to catch up.

This paper explores some of the key issues and challenges of global technology governance based on existing literature. Observing the gap in proactive governance response to the impact and future outlook of emerging technologies in Africa, the paper offers some key considerations for effective technology governance in Africa. The paper particularly argues 
that, amongst other things, technology governance in Africa needs to be informed by the important concerns raised by contemporary investment in decolonisation in Africa. The paper also argues for the pursuit of an inclusive approach that also centralises rural and marginal communities and evaluates the current dominant focus on cities and urban areas in technological innovation and policies.

\section{Managing Risks and Benefits of Technological Innovation}

The Science, Technology and Innovation (STI) Policy has been a key intervention instrument by governments to support and manage scientific knowledge production, technological solutions, and innovation consistent with states' political missions and economic interests (Chaminade \& Lundvall, 2019). According to Chaminade and Lundvall (2019), science policy is specifically concerned with knowledge production for desired economic and societal outcomes, while technology policy is about developing and applying specific technologies that are considered to have strategic value for a country. Innovation policy, then, seeks to intervene in the innovation process from the knowledge production phase to the application of such knowledge to technologies as well as marketing and diffusion of such technologies (Chaminade \& Lundvall, 2019). Thus, this process is important to how institutions seek to manage the benefits and risks of technologies by shaping the direction and impact of these processes. For the OECD (2018), governance in this context is not simply about regulation, but refers to various normative and institutional processes for guiding technology development. Some of these include Research and Development (R\&D) "agenda-setting and mechanisms for public accountability; technology assessment, foresight and science advise; public engagement and science communication; regulation and soft law; and, private sector governance and self-regulation" (OECD., 2018).

Emerging innovations are made possible by, and/or rely on digital technologies and data mining and manipulation (Paunov \& Guellec, 2018). This and several other characteristics of innovation and technology pose new opportunities and challenges for governance as a whole, and technology governance more specifically. Some of such challenges and gaps include (OECD, 2018): inconsistency between some technologies and human values, leading to lack of trust from the public; failure of traditional instruments, such as risk assessment, to robustly apply to new technologies or to be relevant early enough in the development of specific technologies. For example, current regulatory instruments and standards are unlikely to effectively address ethical and safety issues related to artificial intelligence or neurotechnology for the long term specifically because these technologies are still being developed and not much is known about how they will affect society in future. 
The World Economic Forum's Insight report of 2020, while acknowledging that governance challenges can be unique to individual technologies, identified several cross-cutting gaps in technology governance. These include:

\section{Lack of regulations}

Regulatory bodies are not prepared for artificial intelligence's legal consequences and future impact. This is seen in issues raised by facial recognition errors, security breaches on the Internet of Things (IoT), and Blockchain smart contracts exploitation, which current financial regulations cannot address.

\section{Misuse and unintended use}

The misuse and unintended use of technologies can have adverse effects on society. Bitcoin is the most used currency in ransomware payment, yet identifying culprits of crypto-related crimes are challenging due to the nature of the blockchain. Algorithmic processes and errors can be biased, exclude people or have other materially damaging impacts, and authoritarians and other actors can utilise artificial intelligence (AI) for disinformation to adversely shape public opinion and unjustly discredit threatening entities.

\section{Liability and accountability of technology}

It can be very complicated to assign responsibility for the decisions or errors of autonomous systems due to the complicated network of systems and people involved in the creation of such systems and their ability to self-sustain, self-improve, and make decisions autonomously.

\section{Privacy and data sharing}

Most digital technologies rely heavily on data to function or provide the services they are created for. This has increased concerns about intrusion and unauthorised collection of personal data by mobile apps, software and several technologies in everyday use. Ensuring a balance between protecting the privacy and ensuring that these technologies also mind the data they need to operate and develop intervention of lawmakers and regulators is a challenge.

\section{Access and use by law enforcement}

The actual and potential misuse of private information by law enforcement has been a major public concern. These concerns raise questions about policing, surveillance and border control, amongst other things. Existing regulations do not address some of these issues properly.

\section{Cyber and other security concerns}


Cyber-attacks are on the rise and heightened by the COVID-19 pandemic, with the global financial sector witnessing a 238\% increase in attacks between February and April 2020 alone. Other sectors such as the health sector in the United States, and the World Health Organization have been reported to have witnessed a severe rise in cyberattacks. These attacks take different forms and exploit different vulnerabilities, with more potent technologies posing more serious dangers of misuse.

\section{Human supervision}

Minimal human involvement in technologies powered by Al is a growing and important aspect of innovation and confidence in technological products. However, the potential harm and safety risks create a dilemma about how humans should be involved in the operations of systems powered by Al and how this might ensure safety. This concern was aggravated by the COVID-19 pandemic, which forced organisations to reduce human contact.

\section{Cross-border insecurities and restricted data flows}

The transnational nature of $\mathrm{Al}$, blockchain and other technologies expose the limitations of national-level regulations and policies.

Some of these challenges are new to policymakers and stakeholders and require thorough investigation, collaboration and innovative responses. Many states and organisations have reactively responded to challenges with policies after a significant event exposes these challenges and heightens calls for effective governance and regulations. A recent case in point is the recent revelation through over a hundred thousand documents in 68 countries showing how the now defunct Cambridge Analytica manipulated 87 million Facebook profiles to influence voting at an industrial and global scale (Cadwalladr, 2020). Several other incidences involving privacy breaches, errors in autonomous technologies, misuse of data by law enforcement, inappropriate mining of personal data, internet frauds, and others have often shocked society to realise the potential harms of emerging technologies. Campaigns for more ethical technologies have also increased, and researchers, institutions, governments, the private sector and other stakeholders are increasingly beginning to think more proactively about technology governance. Some of the innovative responses to the gaps in technology governance are highlighted in the next section.

\section{Innovative Responses to Technology Governance Challenges}

The Insight report (2020) of the World Economic Forum and Deloitte surveyed some innovative efforts to avoid the potential risks of technologies while maximising their benefits through policy and regulations. The use of ethical governance frameworks that provide guidance and principles on ethical ways to develop technologies is one such effort. Others are; 
- improved collaboration between public and private sectors to co-create regulations, and pursue avenues for responsible development and use of technologies;

- the use of agile and responsive regulations to respond to the agile and responsive nature of technological innovation;

- emulation of the approach of innovation start-ups through the use of sandboxes and accelerators to experiment, test and develop appropriate regulations; improved data sharing and interoperability to ensure that data translates into appropriate results for the public; and,

- collaborating within and across borders to produce effective regulations.

Anticipatory governance is the most promising approach to technology governance. The approach is informed by what is commonly known as Collingridge's dilemma (Genus \& Stirling, 2018). This is because at the early stages of innovation, when it might be cheaper and easier to intervene and course correct, such need for change or intervention may not be fully evident. When the need becomes evident, it might be challenging or expensive to course correct. This dilemma is central to the confusion over how to best respond to innovation and technological development. It is easy to influence such development when the implications are unknown, but difficult to change after they are known (Kudina \& Verbeek, 2019).

Anticipatory governance partly addresses this dilemma by focusing on the management of innovation processes instead of the technological outcomes' risks (Winickoff \& Pfotenhauer, 2018). Thus, it aims to anticipate potential issues, address them in the early stages, steer the innovation in the right direction, and make it inclusive and purposeful. This way, important factors are considered from the beginnings of innovation and public good incorporated into the design and development process of technologies. It is forwardthinking and future-oriented (Conley, 2017). According to Winickoff and Pfotenhauer (2018), there are three promising instrument in the anticipatory governance approach:

- Participatory agenda-setting for mission-driven innovation: this is the use of bottom-up approaches to ensure that innovation strategies align with society's priorities.

- Co-creation and testbeds involve innovation actors from different backgrounds, institutions, and interests collaborating on joint projects for mutual benefits. This promotes a more open and public innovation approach that is participatory and more likely to enhance governance. 
- Design ethics and standardisation phases: this involves using standards to imbue technologies with appropriate values, norms and safeguards. Standardisation is an important intervention in ensuring that the right values and ethical standards are clearly incorporated into technological systems.

These instruments reflect some of the principles and values prominent in conversations on the governance of technologies. The eight principles discussed by Paunov and Guellec (2018) further identify the values and approaches believed to be crucial for the design of innovation policies in the current technological age:

- Develop data access policy for innovation: this should aim to improve data access in ways that enhance competition, re-use and transparency. It should also address ethical issues, intellectual property and privacy.

- Speedy and agile policy response: using adequate policy experiments to support innovation, including experiments that adopt the logic of start-ups in terms of deployment, evaluation, modification and scaling up or down as appropriate.

- Revisit innovation and research support instruments: revisiting traditional support instruments to address their limitations and ensure responsiveness to the behavior of technological innovation.

- Support core technology development and their diffusion: continuous government investment in key innovations to enable them prepare for future emergent technologies. Also, to ensure that technologies are not only used for commercial purposes but for other public goods too.

- Foster collaborative and open innovation: promote collaboration between industry and academia, as well as among businesses, and also pay attention to new and emerging ways of collaborating.

- Enable competition and entrepreneurship.

- Education and training: this will help prepare people for the digital transformation and enable them acquire the right skills that empower them to partake in such transformation.

- Set national policies in view of global markets: facilitating cross-border data access within the confines of respected ethical standards

\section{Minding and Closing the Gaps in Africa}


The growing access and use of emerging technology in Africa have also seen impressive developments in the technology and internet regulatory frameworks by African regional and national governments, aiming to advance the benefits of technology while also addressing potential adverse impacts. According to Boakye (2021) emerging policy areas in Africa include Digital Single Market, digital rights, data protection and privacy, FinTech, digital taxes, start-up and cybersecurity. In this regard, some of the key frameworks include the Declaration of Principles on Freedom of Expression and Access to Information in Africa, the African Union's Digital Transformation Strategy (2020-2030), the African Union's Convention on Cybersecurity and Personal Data, and the African Declaration on Internet Governance. Several other national frameworks exist and the use of sandboxes for regulating innovation, especially in the FinTech sector (Beyers et al., 2018).

These regulations primarily aim to address challenges such as internet access and usage, taxes, fighting misinformation and disinformation, protection of privacy amongst other things, more recently, managing the socio-economic impacts of the COVID-19 pandemic. On the one hand, there is still a major lack of appropriate technology and innovation governance regulations in Africa. In a joint report, the African Union Commission and the Organisation for Economic Co-operation and Development (AUC/OECD, 2021) observed that as of 2021, comprehensive legislation on personal data regulation could only be found in 28 African countries and comprehensive cybercrime laws in on 11 countries. The current technology climate shows a huge gap in regulations and digital strategies and makes countries vulnerable to the abuse and adverse impacts of technological innovations (Center for Strategic and International Studies(CSIS), 2021).

On the other hand, existing regulatory frameworks do not significantly address emerging issues around core and significant technologies such as data infrastructure, Artificial Intelligence and blockchain. Additionally, these frameworks and local regulations suffer challenges elsewhere - not being anticipatory and responsive enough to the modern fluid innovation landscape. It could be argued that since Africa is behind in the development and adoption of these technologies, the issues they raise may not be as pressing as they are in the developed world. However, this must be seen as an advantage and opportunity for more proactive thinking that creates the right and ethical environment for adopting and developing such technologies. It is an opportunity to ensure that those technologies are adopted in ways that take the pressing issues seriously in Africa. This way, Africa is not a data mining site or technological exploitation as witnessed with several defining epochs in history.

In addition to these limitations, the technology governance landscape in Africa is undermined by issues and events such as internet shutdowns witnessed in many African countries in recent years. In the past four years, over 20 cases of internet and social media 
shutdowns by African governments were seen. Governments cited security concerns and prevention of the use of technologies to cause harm as some of the reasons (Giles \& Mwai, 2021). Other issues include social media tax in places like Uganda, where a daily tax of up to 200 Ugandan Shillings was imposed for the use of Facebook, WhatsApp, Twitter and several other social networking sites - forcing millions of users off the platforms. In addition, Uganda witnessed social media bans, interference with elections and an exponential surge in cybercrimes costing the continent billions of dollars, amongst other things (Boakye, 2021; Ratcliffe \& Okiror, 2019). Some of these challenges demonstrate governments' obsession with controlling criticisms by the public and the increased level of exposure of their unacceptable decisions, and maintaining civil mobilisation and resistance against them even when claims about preventing disinformation and misinformation are behind these claims.

The technology governance landscape in Africa is still a wide open field with many issues, possibilities, emerging debates and yet unknown dimensions. While African governments and the private sector critically learn and engage their people and the rest of the world, I outline some key considerations requiring serious attention. These suggestions highlight the intersection of the global trends in addressing the gaps in technology governance as discussed in this paper and address some of the topical social and political challenges that African societies are currently grappling with.

\section{Decolonisation approach}

Policy and regulatory thinking on technological governance in Africa should relate to the ongoing decolonisation debates in Africa. Similar debates around the world are already emerging regarding the role of datafication, algorithmic processes and the technological economy in reproducing imperial and colonial patterns of exclusion, inequalities, marginalisation, western hegemony and the worse aspects of capitalism. Scholars have demonstrated how powerful countries are reinventing colonialism in the global South through technology hegemony, monopoly of technology architecture, surveillance, and data mining. In doing so, the scholars argue, such countries are meting epistemic violence on rural and indigenous people and knowledge systems (Coleman, 2018; Kwet, 2019b, 2019a; Young, 2019). African institutions and leaders should be proactive in thinking about these issues and take the proper steps to ensure that technology in Africa does not become a means of reintroducing these realities. This will require an approach to technology and innovation which seeks to inject important African values during the early stages of innovation, receives important innovation critically - rejecting or adapting aspects that do not promote the well-being of the citizenry. Such an approach should ensure that innovation at all levels ultimately serves the socio-economic, political and cultural wellbeing of Africans. Africa's response to technology also needs to move away from the colonial mindset that loathes and degrades the local while assuming the inherent superiority of western knowledge and technologies. 
A decolonisation approach should also seek to reframe the concepts used in the technology governance space and reframe the debates. Many of the systems and ideas that shape the structures of the technology ecosystem, the assumptions and ideas taken for granted in the technology governance and ethics sphere are based on already problematic perspectives and sources. For example, Arora (2019) argues that despite the globalisation of technologies, the notion of privacy, which is one of the most topical debates, is still ethnocentric. It is informed by empirical evidence drawn from white, middle-class and western demographics. Arora (2019) advocates for an approach that abandons this approach to privacy and its neoliberal market-driven ideologies for a more inclusive approach.

\section{Informed by current needs and future thinking}

Africa's technology governance should be informed by the current socio-economic issues and anticipated future needs. Issues such as corruption, food insecurity, poverty, service delivery, climate change, gender inequality, rural livelihoods vulnerability, amongst several other things. Governance of technology should aim to encourage innovations and technologies that assist in addressing these challenges in effective and efficient ways. Stakeholders should also think in terms of the long-term future. What would these issues look like in the next 50, 100 or more years? What other needs are likely to arise in the future? How can governance response today prepare nations and societies to adequately respond to future and yet unknown potential impacts of technologies?

As a design approach, future thinking considers likely future changes and constants to improve planning and implementation of current projects (Corthell, n.d.). It aims to identify possible future results of current decisions and actions. This way of thinking and strategising limits potential future harm or risks, and potentially saves the time and resources that would be used to fix damages reactively. Future thinking on technology governance requires a thorough understanding of contexts and issues surrounding emerging technology and those that have historically shaped these contexts and issues. It invites a critical examination of the assumptions behind and about design, innovations, their purpose, deployment, target users and the debates surrounding them. It should also be based on a well-informed forecast into the near and distant futures and a deliberate choice of the desirable future amongst possible alternatives.

Another important consideration for future thinking is that innovation is gradually moving towards co-innovation between humans and machines and possibly autonomous innovations by machines, instead of humans beings alone being the source of innovation (Botha, 2019). Machines are increasingly becoming intelligent systems and not simply tools used in productions. The potential of such intelligent systems to replace not only technical jobs but those of lawyers, teachers, medical doctors and accountants is no longer 
a fantasy of a distant future (Botha, 2019). A future where intelligent machines can also innovate raises complex ethical and governance questions. But these questions have to be engaged now, and proactive strategies and instruments developed to support the safe and positively beneficial development of such innovations.

\section{Be in sync with global directions but prioritise Africa's needs}

The transnational nature of core and large technologies makes it difficult to develop governance processes that are removed from global trends. Policymakers and legislators need to pay close attention to global trends on emerging technologies, their impacts and governance frameworks. They should also aim to participate and influence the direction of such global trends to ensure that Africa's interests and values are carried along. Additionally, technology governance will also benefit from current thinking and advocacy for increased regional integration and learn from the failures to implement some of the critical integration arrangements (Hartzenberg, 2011). The fundamental value envisioned in collaborating and working together to achieve desirable outcomes for Africans should also inform conversations about technology governance on the continent.

\section{Focus on rural, marginal communities}

Conversations about innovation are more frequently concerned with or applicable to urban and industrial centres. Some critical technological advances and advocacies seek to address issues like rural agriculture or ensure internet access in the most rural locations. Yet there is generally less attention to the specific ways technological innovations affect rural, indigenous people, refugees and other marginalised communities. These are important but often ignored, excluded and underserved communities in Africa. Yet, the ambitious development goals of the continent will be significantly undermined if these communities remain excluded. This is partly because these communities constitute a significant social and political force. Many African countries, for example, have larger rural populations than urban ones (Saleh, 2021). Thus, technology governance strategies need to think beyond the cities and people at the centre of countries' economies. They must also ensure that these populations are not simply considered potential markets for unexploited profits but aim to protect them and ensure that technologies improve their lives and access to better futures.

\section{Conclusion}

Technology governance is a highly challenging task both at global and national levels. Yet, it is necessary for a safe world and promotes genuine human flourishing. While different technologies may need different approaches to policy and regulation due to the specific challenges they present society with, there are several common issues and broader considerations applicable across innovations. This paper outlined some of the key challenges to the governance of emerging technologies globally and in the African region. 
The paper also discussed key principles and issues that need to be considered regarding technology governance in Africa. African governments, the corporate sector, academic institutions, and other stakeholders need to begin to engage the current state of innovations and technologies and their possible futures and implications for the continent more critically and innovatively. This will require decolonising approaches, informed by contemporary needs and future thinking, sync with global trends while prioritising Africa's interests and needs, and paying attention to rural and marginal communities. The gap between technological innovation and adoption between the West and Africa should not only be seen as a sign of Africa's slow entry into the fourth industrial revolution. It should also be seen as an opportunity to be more purposeful in its participation and rethink innovation in ways that promote the safety, well-being, and flourishing of the continent and its people.

Future research is needed to understand the unique characteristics of the innovation landscape of Africa, the trajectories they take and the factors that shape these trajectories. This will enable governance intervention to prevent harm and manage risk from the early stages of local innovation. Studies should also aim to understand how local innovation and core African needs and values interact with larger technological innovations. Also, how the processes of technology adoption and diffusion in Africa work. This could assist policy and governance decisions to control better adoption and diffusion processes that are detrimental to the well-being of African societies. Finally, future research should establish inclusive, just and equitable technological governance processes. They could do so by investigating the impact of the emphasis on cities and rural communities and ensuring that rural and marginal communities are also at the heart of innovation and thinking about technologies.

\section{Acknowledgement}

The author acknowledges the support of South Africa's National Research Foundation (NRF) through the NRF/SARChI Chair in Sustainable Local Livelihoods at the University of KwaZulu-Natal.

\section{References}

Arora, P. (2019). Decolonising Privacy Studies. Television \& New Media, 20(4), 366-378. https://doi.org/10.1177/1527476418806092

AUC/OECD. (2021). Africa's Development Dynamics 2020: Digital Transformation for Quality Jobs. , AUC, Addis Ababa/OECD Publishing, Paris. https://doi.org/10.1787/0a5c9314-en 
Beyers, N., Gray, J., \& Hougaard, C. (2018). Regulation for Innovation. Centre for Financial Regulation \& Inclusion.

Boakye, B. (2021). Tech Policy in Africa: Emerging Trends in Internet Law and Policy. Institute for Global Change. https://institute.global/policy/tech-policy-africaemerging-trends-internet-law-and-policy

Botha, A. P. (2019). A mind model for intelligent machine innovation using future thinking principles. Journal of Manufacturing Technology Management, 30(8), 1250-1264. https://doi.org/10.1108/JMTM-01-2018-0021

Cadwalladr, C. (2020, January 4). Fresh Cambridge Analytica leak 'shows global manipulation is out of control.' The Observer. https://www.theguardian.com/uknews/2020/jan/04/cambridge-analytica-data-leak-global-election-manipulation

Center for Strategic and International Studies(CSIS). (2021). Digital Africa: Leveling Up through Governance and Trade. https://www.csis.org/analysis/digital-africaleveling-through-governance-and-trade

Chaminade, C., \& Lundvall, B.-Å. (2019). Science, technology, and innovation policy: Old patterns and new challenges. In Oxford Research Encyclopedia of Business and Management.

Coleman, D. (2018). Digital colonialism: The 21st century scramble for Africa through the extraction and control of user data and the limitations of data protection laws. Mich. J. Race \& L., 24, 417.

Conley, S. N. (2017). Assessing the Societal Implications of Emerging Technologies: Anticipatory Governance in Practice. Science and Public Policy, 44(6), 877-879. https://doi.org/10.1093/scipol/scx028

Corthell, L. P. (n.d.). What is Futures Thinking? / Mad*Pow. MAD POW. Retrieved November 19, 2021, from https://www.madpow.com/insights/2021/1/whatfutures-thinking

Genus, A., \& Stirling, A. (2018). Collingridge and the dilemma of control: Towards responsible and accountable innovation. Research Policy, 47(1), 61-69.

Giles, C., \& Mwai, P. (2021, January 14). Africa internet: Where and how are governments blocking it? BBC News. https://www.bbc.com/news/world-africa-47734843

Hartzenberg, T. (2011). Regional Integration in Africa (SSRN Scholarly Paper ID 1941742). Social Science Research Network. https://doi.org/10.2139/ssrn.1941742 
Joshi, A., Bollen, L., Hassink, H., De Haes, S., \& Van Grembergen, W. (2018). Explaining IT governance disclosure through the constructs of IT governance maturity and IT strategic role. Information \& Management, 55(3), 368-380.

Kudina, O., \& Verbeek, P.-P. (2019). Ethics from Within: Google Glass, the Collingridge Dilemma, and the Mediated Value of Privacy. Science, Technology, \& Human Values, 44(2), 291-314. https://doi.org/10.1177/0162243918793711

Kwet, M. (2019a). Digital Colonialism: South Africa's Education Transformation in the Shadow of Silicon Valley. Available at SSRN 3496049.

Kwet, M. (2019b). Digital colonialism: US empire and the new imperialism in the Global South. Race \& Class, 60(4), 3-26.

OECD. (2018). OECD Science, Technology and Innovation Outlook 2018: Adapting to Technological and Societal Disruption. OECD. https://doi.org/10.1787/sti_in_outlook-2018-en

OECD., K. (2018). OECD Science, Technology and Innovation Outlook 2018. OECD Publishing Paris.

Paunov, C., \& Guellec, D. (2018). Chapter 3. Perspectives on innovation policies in the digital age. In OECD Science, Technology and Innovation Outlook 2018. OECD Publishing. https://www.oecd-ilibrary.org/science-and-technology/oecd-sciencetechnology-and-innovation-outlook-2018_sti_in_outlook-2018-en

Ratcliffe, R., \& Okiror, S. (2019, February 27). Millions of Ugandans quit internet services as social media tax takes effect. The Guardian. https://www.theguardian.com/global-development/2019/feb/27/millions-ofugandans-quit-internet-after-introduction-of-social-media-tax-free-speech

Saleh, M. (2021). Africa: Urbanisation rate by country 2020. Statista. https://www.statista.com/statistics/1223543/urbanization-rate-in-africa-bycountry/

Sirisomboonsuk, P., Gu, V. C., Cao, R. Q., \& Burns, J. R. (2018). Relationships between project governance and information technology governance and their impact on project performance. International Journal of Project Management, 36(2), 287300.

Winickoff, D. E., \& Pfotenhauer, S. M. (2018). Chapter 10. Technology governance and the innovation process. In OECD Science, Technology and Innovation Outlook 2018. 
OECD Publishing. https://www.oecd-ilibrary.org/science-and-technology/oecdscience-technology-and-innovation-outlook-2018_sti_in_outlook-2018-en

World Economic Forum, \& Deloitte. (2020). Global Technology Governance Report 2021 [Insight Report]. World Economic Forum. https://www.weforum.org/reports/global-technology-governance-report-2021/

Young, J. C. (2019). The new knowledge politics of digital colonialism. Environment and Planning A: Economy and Space, 51(7), 1424-1441. 